\title{
Desenvolvimento da camomila, rendimento e qualidade do óleo essencial em diferentes idades de colheita
}

\author{
AMARAL, W. ${ }^{1 *}$; DESCHAMPS, C. ${ }^{1}$; MACHADO, M.P. ${ }^{1}$; KOELER, H.S. ${ }^{1}$; SCHEER, A.P. ${ }^{2}$; CÔCCO, L.C. ${ }^{2}$ \\ ${ }^{1}$ Universidade Federal do Paraná, Rua dos Funcionários no 1540, CEP 80035-050 Curitiba - Brasil *posunibem@ \\ faculdadeespirita.com, ${ }^{2}$ Universidade Federal do Paraná, Centro Politécnico, CEP: 81530-990 Curitiba, Paraná \\ - Brasil
}

RESUMO: A camomila é uma planta herbácea, anual e aromática com várias propriedades medicinais. No Brasil, vem sendo cultivada em área representativa na região Sul devido, principalmente, às exigências climáticas da espécie, e por ter sido introduzida por imigrantes europeus nesta região. A colheita da camomila é realizada em várias colheitas, contudo, a idade adequada da planta para o início desta atividade, objetivado a maior produção de capítulos florais, bem como o rendimento e qualidade de óleos essenciais, ainda não foi determinada para a espécie. Neste trabalho, investigou-se o efeito de diferentes épocas de colheita no desenvolvimento de capítulos florais e no acúmulo e qualidade do óleo essencial da camomila. O experimento foi conduzido no município de Piraquara (PR). O delineamento experimental foi inteiramente casualizado, com cinco tratamentos (85, 92, 99, 106 e 113 dias após a emergência das plântulas) e cinco repetições. Após cada colheita, avaliou-se o acúmulo de massa seca de capítulos, rendimento, produção e composição do óleo essencial. A extração de óleo foi realizada por hidrodestilação e as amostras analisadas por cromatografia gasosa. Concluiu-se que aos 85 dias após a emergência (DAE) os capítulos apresentaram maior rendimento de óleo. Porém, após três semanas ocorreu a maior produção de massa de capítulos, resultando em maiores médias de produtividade de óleo essencial. A partir de 113 DAE houve redução do rendimento de óleo essencial e no teor de alguns constituintes.

Palavras-chave: Chamomilla recutita, óleo essencial, rendimento

\begin{abstract}
Development of chamomile and essential oil yield and quality at different harvesting times. Chamomile is an aromatic herb with many medicinal properties. In Brazil, it is cultivated on an extensive area in the Southern region mainly because of its climatic conditions for this culture. Chamomile harvesting is done by several cuttings of the entire plant, but the ideal starting point of this activity to obtain high production of flower heads has not been determined. This work investigated the effect of the harvesting period of chamomile on flower head development and essential oil accumulation. The experiment was carried out at field conditions in Piraquara, Paraná, Brazil. The experimental design was completely randomized with five treatments $(85,92,99,106$ and 113 days after emergency) and five replications. After each harvest, dry mass accumulation and essential oil yield and quality were evaluated. Essential oil extraction was performed by hydrodistillation, and the sample was analyzed by gas chromatography. When harvested 85 days after emergency, the flower heads presented the highest essential oil content, but three weeks later the highest flower head dry mass was obtained, which resulted on great essential oil productivity. From 113 days after emergency, there is a reduction in essential oil yield and production.
\end{abstract}

Keywords: Chamomilla recutita, essential oil, yield

\section{INTRODUÇÃO}

A camomila [Chamomilla recutita (L.) Rauschert] é uma planta herbácea, anual e aromática, originária do sul e leste da Europa, bem como do oeste asiático (Lorenzi \& Matos, 2008).
Seus capítulos florais possuem óleo essencial composto por terpenos, flavonoides e outras substâncias orgânicas (Salamón, 1992; Teske \&

Trentini, 1997; Silva Júnior, 2003). O óleo essencial 
da camomila é de interesse alimentício, cosmético e principalmente farmacológico, devido às suas ações antiinflamatória, bactericida, antisséptica, calmante, cicatrizante e antiflogística (Rodríguez et al., 1996; Simões \& Spitzer, 1999; Amaral et al., 2003; Mapeli et al., 2005).

A determinação da época da colheita de plantas medicinais e aromáticas é essencial para a obtenção de maior teor de óleo essencial e melhor qualidade (Carvalho Filho et al., 2006). Em Cymbopogon citratus o rendimento de óleo essencial decresceu linearmente em função da idade das plantas (Leal et al., 2003), e para plantas de Ocimum basilicum colhidas em duas épocas, o teor de óleo essencial foi maior na primeira colheita (Tansi \& Nacar, 2000). Segundo Silva Júnior (2003), o florescimento da camomila cv. Mandirituba (Corrêa Júnior, 1995), atualmente plantada no Estado do Paraná, inicia-se a partir dos 85 dias após a semeadura, sendo o ponto de colheita determinado quando a maior parte dos capítulos florais está aberta (Biasi \& Deschamps,2009), e, estando a curvatura das lígulas voltadas para baixo, seguido de murchamento, é indicativo de que o ponto de colheita foi ultrapassado.

O óleo essencial da camomila possui a-bisabolol que apresenta propriedades antiinflamatórias e antiseptica (Torrado et al., 1995). Avaliando cultivares de camomila provenientes do Canadá, Letchamo \& Marquard (1993) observaram tendência de decréscimo no conteúdo de óleo essencial a cada colheita afetando também a concentração dos constituintes, de forma que a maior percentagem de $\alpha$-bisabolol foi obtida nas primeiras colheitas, com posterior decréscimo. O conteúdo de camazuleno, uma das substancias presente no óleo essencial de camomila com propriedades analgésicas, anti-infecciosa e antialérgica, por sua vez, apresentou oscilação entre as colheitas.

No Paraná, a produção de camomila está concentrada nos municípios de Mandirituba e São José dos Pinhais (Costa \& Doni-Filho, 2002). O seu cultivo nestas regiões é realizado utilizando-se somente a cultivar Mandirituba, que apresenta cerca de $0,86 \%$ de óleo essencial presente nos capítulos florais, com 27 a $35 \%$ de camazuleno e 7 a $11 \%$ de a-bisabolol (Corrêa Júnior, 1995).

No estado de São Paulo, Corrêa Júnior (1994) observou que as quatro primeiras colheitas apresentaram maior percentual de óleo essencial, com decréscimo significativo nas duas últimas colheitas. O teor de $\alpha$-bisabolol decresceu ao longo das colheitas, sendo que entre a primeira e a sexta colheita houve um decréscimo de aproximadamente $60 \%$. O óleo essencial apresentou teores de camazuleno superiores na última colheita com aumento de $72 \%$.
Este trabalho teve por objetivo avaliar a influência de diferentes idades de colheita no desenvolvimento de capítulos florais, rendimento, produção e qualidade do óleo essencial de camomila, nas condições do município de Piraquara (PR).

\section{MATERIAL E MÉTODO}

O experimento foi conduzido no Município de Piraquara (PR) (2532'07" S; 4903'54" W; altitude média de $950 \mathrm{~m})$. O solo da área experimental é classificado como cambissolo hálico (EMBRAPA, 1999), e sua análise química prévia apresentou as seguintes características: $\mathrm{pH}$ em CaCl2 $=5,05 ; \mathrm{Al}^{+3}$ $=0,15 \mathrm{cmol}_{\mathrm{c}} \mathrm{dm}^{-3} ; \mathrm{H}^{+}+\mathrm{Al}^{+3}=5,6 \mathrm{cmol}_{\mathrm{c}} \mathrm{dm}^{-3} ; \mathrm{Ca}^{+2}=$ $3,48 \mathrm{cmol}_{\mathrm{c}} \mathrm{dm}^{-3} ; \mathrm{Mg}+2=1,64 \mathrm{cmol}_{\mathrm{c}} \mathrm{dm}^{-3} ; \mathrm{K}+=0,13$ $\mathrm{cmol}_{\mathrm{c}} \mathrm{dm}^{-3} ; \mathrm{P}=3,40 \mathrm{mg} \mathrm{dm}^{-3} ; \mathrm{C}=28,40 \mathrm{mg} \mathrm{dm}^{-3}$; saturação por bases $=46,86 \%$.

Foi aplicado $2.500 \mathrm{~kg} \mathrm{ha}^{-1}$ de calcário tipo filler (100\% PRNT) a lanço, com posterior incorporação na profundidade de $0-10 \mathrm{~cm}$, para a correção do pH. A adubação foi realizada com 40 $\mathrm{kg} \mathrm{ha}^{-1}$ de nitrogênio na forma de ureia, $120 \mathrm{~kg} \mathrm{ha}^{-1}$ de $\mathrm{P}_{2} \mathrm{O}_{5}$ na forma de superfosfato triplo e $80 \mathrm{~kg} \mathrm{ha}^{-1}$ de $\mathrm{K}_{2} \mathrm{O}$ na forma de cloreto de potássio (Raij et al., 1996).

As sementes da camomila cv. Mandirituba foram produzidas na safra de 2003 , sendo beneficiadas em mesa de gravidade DAMAS ${ }^{\circledR}$ tipo Lanta-k, no Laboratório de Tecnologia de Sementes da UFPR, em Curitiba - PR. A análise da germinação foi realizada no Laboratório da Empresa Paranaense de Classificação de Produtos (CLASPAR/SEAB), e apresentou índice de germinação de 35\%.

Foi realizado o plantio em linha utilizando-se $2,0 \mathrm{~kg} \mathrm{ha}^{-1}$ de sementes espalhadas manualmente diretamente no local definitivo, em julho de 2004. $\mathrm{Na}$ semeadura utilizou-se fubá de milho como veículo na proporção de 50:1 (v:v) de sementes em espaçamento de $0,50 \mathrm{~m}$ entre linhas (Costa \& Doni-Filho, 2002). Os tratamentos consistiram nas diferentes idades de colheita 85, 92, 99, 106 e 113 dias após a emergência (DAE). As colheitas foram realizadas manualmente, para cada idade de colheita.

O delineamento experimental foi inteiramente casualizado com cinco repetições. As parcelas possuíam 2,0 m x 3,0 m, sendo $2,0 \mathrm{~m}^{2}$ de parcela útil, com distância de 1,0 m entre cada parcela. As variáveis analisadas em cada colheita foram massa seca dos capítulos, rendimento do óleo essencial, produção do óleo essencial e composição do óleo essencial.

Após a colheita de todos os capítulos florais da parcela útil de cada tratamento, procedeu-se a secagem em secador (FANEM - Mod. 320 SE)

Rev. Bras. PI. Med., Campinas, v.16, n.2, p.237-242, 2014. 
com circulação de ar, a temperatura de $65^{\circ} \mathrm{C}$ por 10 horas (Borsato et al., 2005). Para determinação do teor de óleo em base seca, foram retiradas subamostras de $20 \mathrm{~g}$ e secas em secador a $65^{\circ} \mathrm{C}$ até massa constante.

A extração de óleo essencial foi realizada no Laboratório de Ecofisiologia da UFPR por hidrodestilação, durante 4 horas e 30 minutos, em aparelho graduado tipo Clevenger (WASICKY, 1963) utilizando-se $46 \mathrm{~g}$ de capítulos secos. Após a extração, as amostras foram coletadas e armazenadas $a-20^{\circ} \mathrm{C}$ onde permaneceram até o momento da análise.

Utilizou-se um cromatógrafo gasoso Varian, modelo CP- 3800, com detector FID (CG/FID), para quantificar os constituintes do óleo essencial. Para a separação cromatográfica, utilizou-se uma coluna capilar Chrompack, de sílica fundida CP-SIL PONA CB, 0,25 mm de diâmetro interno, 100m de comprimento e $0,50 \mu \mathrm{m}$ de filme líquido. As condições de análise otimizadas para esta coluna foram as seguintes: a) temperatura do injetor: $200^{\circ} \mathrm{C}$, split 1 : 100; b) quantidade de amostra injetada: 1,0 $\mu \mathrm{L}$; c) gás de arraste: hélio a $1,0 \mathrm{~mL} /$ minuto na temperatura de $120^{\circ} \mathrm{C}$; d) gás de make up: ar sintético, nitrogênio e hidrogênio; e) temperatura do detector FID: $300^{\circ} \mathrm{C}$; f) programação de temperatura do forno: 22 minutos a $120^{\circ} \mathrm{C}$, elevação de temperatura a $230^{\circ} \mathrm{C}$ na razão de $10^{\circ} \mathrm{C}$ permanecendo por 20 minutos; g) tempo total de corrida: 53 minutos. A identificação dos constituintes químicos foi baseada em trabalho de Borsato et al. (2008), que utilizaram a biblioteca NIST 98 (Varian Inc.) do CG/MS do LACAUT ets.

As análises estatísticas foram feitas utilizando-se o programa MSTAT-C (Nissen, 1993). As variâncias dos tratamentos foram testadas quanto à homogeneidade pelo teste de Bartlett $\mathrm{e}$ os valores médios foram submetidos à análise de regressão.

\section{RESULTADO E DISCUSSÃO}

A massa seca dos capítulos florais da camomila cv. Mandirituba aos 85 DAE foi de $128,6 \mathrm{~kg}$ $\mathrm{ha}^{-1}$, sendo observado aumento até a colheita de 106 $\operatorname{DAE}\left(499,6 \mathrm{~kg} \mathrm{ha}^{-1}\right)$, a partir da qual ocorreu redução para 455,2 kg ha-1 aos 113 DAE (Figura 1A). Amaral et al. (2012), encontraram produção de $510,0 \mathrm{~kg} \mathrm{ha}^{-1}$ de massa seca de capítulos florais de camomila cv. Mandirituba, demonstrando que a colheita de 106 DAE apresentou resultados próximos aos obtidos para a mesma cultivar em outros estudos. Estes resultados sugerem que a idade de colheita da camomila cv. Mandirituba mais apropriada para a obtenção de maior massa seca de capítulos é aos 106 DAE. Corrêa Júnior (1994), também observou que ocorrem diferenças na produção de massa seca dos capítulos de camomila em diferentes colheitas, porém os cortes foram realizados nas mesmas plantas.

Os capítulos florais colhidos aos 85 DAE apresentaram o maior rendimento de óleo essencial $\left(4,42 \mu \mathrm{L} \mathrm{g}^{-1} \mathrm{~ms}\right)$, ocorrendo decréscimo nas colheitas subsequentes. Aos 113 DAE o rendimento de óleo essencial foi de $1,59 \mu \mathrm{Lg}^{-1} \mathrm{~ms}$ (Figura 1B), o que significa uma redução de aproximadamente $75 \%$, quando comparado com a colheita realizada aos 85 DAE. O teor de óleo essencial de $0,44 \%$ encontrado aos 85 DAE está de acordo com o teor de óleo essencial de camomila exigido pela Farmacopéia Brasileira para a comercialização $(0,40 \%)$ (Wagner \& Bladt, 1995), sendo que o teor de óleo essencial obtido aos 113 DAE $(0,16 \%)$ está muito abaixo. A densidade de tricomas glandulares é um dos fatores que podem ter contribuído para a diminuição no rendimento de óleo essencial. Werker et al. (1993) observaram em manjericão que a densidade de tricomas diminui com a expansão e acúmulo de massa seca das folhas. A menor atividade metabólica em função da idade dos tricomas glandulares também pode ter resultado na redução do rendimento de óleo essencial como observado em Mentha x Piperita por McConkey et al, (2000). Contudo, futuros estudos poderão demonstrar se estes fatores contribuíram realmente para a redução do rendimento de óleo essencial em camomila.

A maior produtividade de óleo essencial $\left(1,54 \mathrm{~L} \mathrm{ha}^{-1}\right)$ foi atingida aos $99 \mathrm{DAE}$, havendo acentuada redução na produtividade aos $113 \mathrm{DAE}$ $\left(0,63 \mathrm{~L} \mathrm{ha}^{-1}\right)$ (Figura 1C), isto devido ao menor rendimento de óleo essencial aos $113 \mathrm{DAE}$, segundo dados já citados. Resultados semelhantes foram encontrados em camomila por El-Hamidi et al. (1965) e Letchamo \& Marquard (1993). Porém, a produtividade de óleo essencial obtida para camomila cv. Mandirituba, por Amaral et al. (2012), foi de 2,40 L ha-1, muito acima aos resultados encontrados no presente estudo, o que pode estar relacionado com o ambiente devido a forte influência na produtividade de óleo.

A porcentagem dos constituintes identificados no óleo essencial de camomila cv. Mandirituba não teve muita variação nas diferentes idades de colheita. Porém, aos 113 DAE não foi constatada a presença da artemísia cetona no óleo essencial analisado. Também, na última colheita o óxido de cariofileno foi encontrado em baixa porcentagem, comparado às demais colheitas. Em todas as colheitas os constituintes majoritários do óleo essencial de camomila cv. Mandirituba foram: óxido de bisabolol A, óxido de bisabolol $B$, cariofileno e a-bisabolol (Tabela 1). Em outros estudos foram observados redução do constituinte $\alpha$-bisabolol ao longo das colheitas (Letchano \& Marquard,

Rev. Bras. PI. Med., Campinas, v.16, n.2, p.237-242, 2014. 

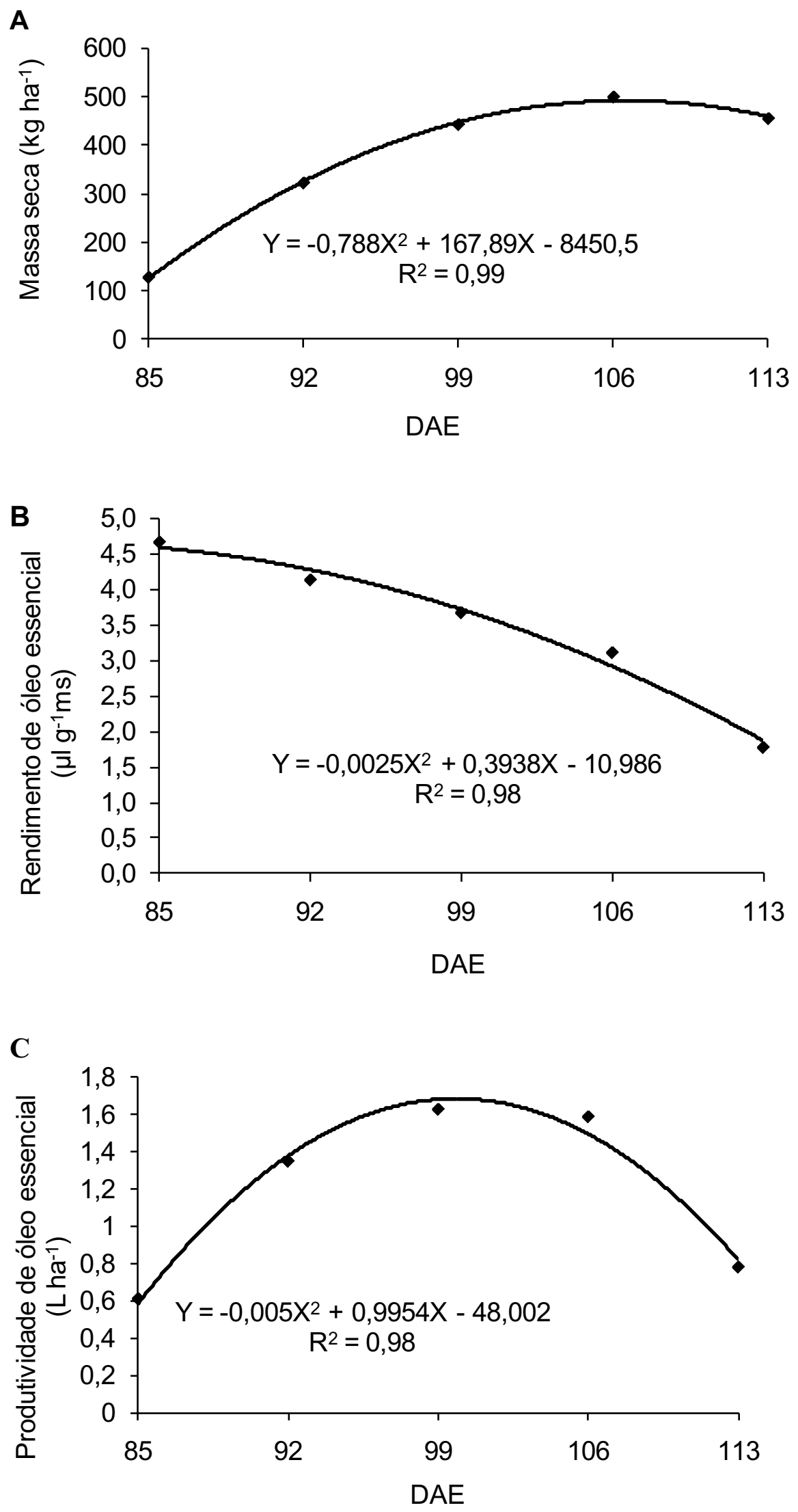

FIGURA 1. Efeito de diferentes idades de colheita de camomila [Chamomilla recutita (L.) Rauschert] cv. Mandirituba. (A) Massa seca dos capítulos. (B) Rendimento do óleo essencial. (C) Produtividade do óleo essencial. Priraquara-PR, 2005. 
TABELA 1. Constituintes (\%) do óleo essencial de camomila [Chamomilla recutita (L.) Rauschert] cv. Mandirituba, em função da idade de colheita. Piraquara-PR, 2005.

\begin{tabular}{llllll}
\hline Constituintes & \multicolumn{7}{l}{ Dias após a emergência (DAE) } \\
\cline { 2 - 6 } & $\mathbf{8 5}$ & $\mathbf{9 2}$ & $\mathbf{9 9}$ & $\mathbf{1 0 6}$ & $\mathbf{1 1 3}$ \\
\hline a-Pineno & 1,30 & 0,60 & 0,93 & 1,03 & 0,69 \\
Artemísia cetona & 1,05 & 0,66 & 0,44 & 0,56 & 0,00 \\
Cariofileno & 13,66 & 18,33 & 13,95 & 8,05 & 12,89 \\
Óxido de Cariofileno & 4,07 & 3,70 & 3,90 & 3,40 & 0,41 \\
Óxido de Bisabolol A & 22,08 & 23,64 & 24,62 & 28,47 & 25,64 \\
Óxido de Bisabolol B & 21,38 & 19,52 & 21,09 & 23,08 & 20,10 \\
a-Bisabolol & 11,65 & 9,99 & 11,22 & 9,82 & 10,21 \\
Óxido de Bisabolona & 4,63 & 4,31 & 5,21 & 4,81 & 4,45 \\
Camazuleno & 5,88 & 5,37 & 6,09 & 5,05 & 5,12 \\
\hline Total identificado & 85,70 & 86,12 & 87,45 & 84,27 & 79,51 \\
\hline
\end{tabular}

1993; Corrêa Júnior, 1994). Amaral et al. (2008), testando fontes e doses de adubos para a cultivar Mandirituba, coletando aos 99 DAE, encontraram valores semelhantes ao do presente estudo para a porcentagem de camazuleno $(4,45 \%-5,80 \%)$.

\section{CONCLUSÃO}

As idades de colheita da camomila cv. Mandirituba afetam o rendimento do óleo essencial. Colheitas realizadas aos 106 DAE proporcionaram maior produção de biomassa dos capítulos, e consequentemente maior produtividade de óleo essencial, porém o maior rendimento de óleo essencial foi alcançado aos 85 DAE. A partir de 113 DAE houve redução do rendimento do óleo essencial e no teor de alguns constituintes.

\section{REFERÊNCIA}

AMARAL, F.M.M. et al. Avaliação da qualidade de drogas vegetais comercializadas em São Luíz - Maranhão. Revista Brasileira de Farmacognosia, v.13, p.27-30, 2003.

AMARAL, W. et al. Desenvolvimento, rendimento e composição de óleo essencial de camomila [Chamomilla recutita (L.) Rauschert] sob adubação orgânica e mineral. Revista Brasileira de Plantas Medicinais, v.10, p.1-8, 2008.

AMARAL, W. et al. Avaliação de germoplasma de camomila e densidade de semeadura na produção e composição do óleo essencial. Horticultura Brasileira, v.30, p.195-200, 2012.

BIASI, L.A.; DESCHAMPS, C. Plantas aromáticas do cultivo à produção de óleo essencial. Curitiba: Layer Studio Gráfico e Editora Ltda, 2009. 160p.

BORSATO, A.V. et al. Secagem da camomila [Chamomilla recutita (L.) Raeuchert] com cinco vazões específicas do ar. Revista Brasileira de Plantas Medicinais, v.7, p.65-71, 2005.
BORSATO, A.V. et al. Propriedades físico-químicas do óleo essencial de camomila [Chamomilla recutita (L.) Rauschert] submetida à secagem em camada fixa. Revista Brasileira de Plantas Medicinais, v.10, p.2430, 2008.

CARVALHO FILHO, J.L.S. et al. Influence of the harvesting time, temperature and drying period on basil (Ocimum basilicum L.) essential oil. Revista Brasileira de Farmacognosia, v.16, n.1, p.24-30, 2006.

CORREAA JÚNIOR, C. "Mandirituba": nova cultivar brasileira de camomila. Horticultura Brasileira, v.13, n.1, p.61, 1995.

CORREAAJÚNOR, C. Influência das adubações orgânica e química na produção de camomila\{Chamomila recutita (L.)Rauschert\}e do seu óleo essencial. Botucatu- 1994. 95 f. Dissertação de mestrado Faculdade de Ciências Veterinárias - UNESP.

COSTA, M.A.D.; DONI-FILHO, L. Aspectos do processo de produção agrícola na cultura da camomila [Chamomilla recutita (L.) Rauschert] no Município de Mandirituba, Paraná. Visão Acadêmica, v.3, p.49-56, 2002.

EL-HAMIDI, A. et al. The effect of fertilizer levels on growth, yield and oil production of Matricaria chamomilla. Lloydia, v.28, n.4, p.245-51, 1965.

EMBRAPA. Sistema Brasileiro de Classificação de Solos. Rio de Janeiro: EMBRAPA -CNPS, 1999.

LEAL, T.C.A.B. et al. Produção de biomassa e oleo essencial em plantas de capim cidreira [Cymbopogon citrates (DC.) Stapf]. Revista Brasileira de Plantas Medicinais, v.5, n.2, p.61-4, 2003.

LETCHAMO, W.; MARQUARD, R. The pattern of active substances accumulation in camomile genotypes under different growing conditions and hervesting frequencies. Acta Horticulturae, n.331, p.357-61, 1993.

LORENZI, H.; MATOS, F.J. Plantas medicinais do Brasil: nativas e exóticas cultivadas. Nova Odessa: Instituto Plantarum, 2008. 512p.

MAPELI, N.C. et al. Produção de biomassa e de óleo essencial dos capítulos florais da camomila em função de nitrogênio e fósforo. Horticultura Brasileira, v.23, p.42-46, 2005.

MCCONKEY M.E. et al. Developmental regulation of monoterpene biosynthesis in the glandular trichomes 
of peppermint. Plant Phisioloy, n.122, p.215-23, 2000.

NISSEN, O. MSTAT-C. A Microcomputer for Design, management, and analysis of Agronomic Research Experiments. Version 2.11. East Lansing, Michigan State University, 1993. 300p.

PAVAN, M. A. et al. Manual de análise química de solo e controle de qualidade. Londrina: IAPAR, 1992. 39 p.

RAIJ, B.V. et al. Recomendações de adubação e calagem para o Estado de São Paulo. Campinas: Instituto Agronômico \& Fundação IAC, 1996. 285p.

RODRÍGUEZ, F.M. et al. Actividad espasmolitica del extrato fluido de Matricaria (Manzanilla) en organos ailados. Revista cubana de Plantas Medicinales, v.1, n.1, p.19-24, 1996.

SALAMÓN, I. Production of chamomile [Chamomilla recutita (L.) Rauschert] in Slovakia. Journal of herbs, spices and medicinal plants, v.1, n.1-3, p.37-45, 1992.

SILVA JÚNIOR, A. A. Essentia Herba: Plantas Bioativas. Vol.1. Florianópolis: Epagri, 2003. 441p.

SIMEPAR - Sistema Meteorológico do Paraná, Estação Meteorológica de Pinhais, Curitiba, 2004.

SIMÕES, C. M. O.; SPITZER, V. Óleos voláteis. In:
SIMÕES, C.M.O.; SCHENKEL, E. P.; GOSMANN, G.; MELLO, J. C. P. DE; MENTZ, L. A.; PETROVCK, P. R. (Eds.). Farmacognosia: da planta ao medicamento. Porto Alegre: UFRGS, 1999.

TANSI, S.; NACAR, S. First cultivation trials of lemon basil (Ocimum basilicum var. citriodorum) in Turkey. Pakistan Journal of Biological Sciences, v.3, n.3, p.395-7, 2000.

TESKE, M.; TRENTINI. A. M. M.; Herbarium compêndio de Fitoterapia. Curitiba: Herbarium Laboratório Botânico, 1997. p.69-71.

TORRADO, S. et al. Effect of dissolution profile and (-)-alpha-bisabolol on the gastrotoxicity of acetylsalicylic acid. Pharmazie, v.50, p.141-3, 1995.

WAGNER, J. C.; BLADT, S. Plant drug analysis: a thin layer chromatography atlas. 2 ed., Berlin: Springer, 1995. p.384.

WASICKY, R. Uma modificação do aparelho de clevenger para extração de óleos essenciais. Revista Faculdade de farmácia e Bioquímica, v.1, n.1, p.77-81, 1963.

WERKER E. et al. Glandular hairs and essential oil in developing leaves of Ocimum basilicum L. (Lamiaceae). Annals of Botany, v.71, p.43-50, 1993. 